\title{
Referencias musicales en la pintura de juan gris
}

\section{Musical references in the painting of juan gris}

DOI: $10.46932 / s f j d v 2 n 5-135$

Received in: Oct 1st, 2021

Accepted in: Dec 30th, 2021

\author{
José Antonio Martínez-Pando \\ Licenciado en Antropología Social y Cutural (UNED) \\ Doctorando en Ciencias Sociales (Antropología) (UCAM) \\ Av. de los Jerónimos, 135, 30107 Guadalupe de Maciascoque, Murcia, Spain \\ E-mail: ppcart@hotmail.com
}

\begin{abstract}
RESUMEN
A diferencia de lo que sucede con Georges Braque, del que se tiene constancia de su amor por la música y de su habilidad de tocar varios instrumentos con cierta maestría, de Juan Gris no se habla de ninguna de estas habilidades, ni tan siquiera de que fuera un melómano. Sin embargo, su obra pictórica está cuajada de referencias musicales, manifestadas principalmente en la guitarra española, aunque otros instrumentos como clarinetes, violines, violones, mandolinas e incluso partituras, son una constante en su obra. El cubismo, como cualquier otra corriente, tuvo su influencia en la pintura, escultura, arquitectura, literatura y, por supuesto, en la música. En este trabajo se estudia el nivel relevante que la música ocupa en la obra de este genio del cubismo sintético, así como lo que supone una clara transversalidad de todas las manifestaciones artísticas.
\end{abstract}

Palabras clave: Juan Gris, cubismo sintético, cubismo y música, vanguardias siglo XX.

\begin{abstract}
Contrary to what we know about Georges Braque, of which it is widely known that he loved music and he was even able to master several musical instruments, no one speaks of any of these skills about Juan Gris, not even known as a music lover. Nevertheless, his paintings are crowded with musical references mainly focussed on the Spanish guitar, although some other instruments are constantly shown in his works like clarinets, violins, cellos, mandolins and even music scores. This research studies how much music is present in the work of this genius of synthetic cubism. Besides, in this piece of work, it is also pointed a view of the transversally in arts.
\end{abstract}

Keywords: Juan Gris, synthetic cubism, cubism and music, 20th century vanguards.

\section{INTRODUCCION}

\subsection{EL CUBISMO Y EL MUNDO DE JUAN GRIS}

El cubismo se encuadra en una de las primeras vanguardias artísticas que nacerán a principios del siglo XX. Un prodigioso siglo en el que se suceden las guerras más terribles que jamás haya visto la humanidad con los descubrimientos científicos más destacados y que, en realidad, serán solo la punta del 
iceberg de los avances tecnológicos que se verán en el futuro. El arte en su totalidad, independientemente de la disciplina de la que hablemos, no es ajeno a las tumultuosas revoluciones de este fascinante siglo.

Se habla de Juan Gris como el tercer representante del cubismo tras las alargadas sombras de Georges Braque y del genial malagueño, Pablo Picasso, quien "siempre tuvo una relación ambigua con Gris, le llamaba maliciosamente le savant du cubisme.” (Jimenez-Blanco, 2013: 3)

"El nombre de Juan Gris se asocia siempre al cubismo, y no es extraño porque toda la pintura que realizó en su corta vida (1887-1927) se desarrolló, de un modo u otro, en relación con el cubismo. Pero la obra de Gris ni es simple ni fácil de caracterizar. Es, desde luego, cubista. Pero en ella hay otros factores a tener en cuenta. Uno de ellos es su profundo respeto por la tradición pictórica occidental, o al menos por cierta parte de ella: la que enfatiza un sentido ordenador de la forma que nos lleva a pensar en el clasicismo. Por eso, se ha apuntado como uno de los aspectos fundamentales de la obra de Gris el deseo de conciliar expresión moderna y tradición clásica.” (Jimenez-Blanco, 2013: 2)

"La presencia de los instrumentos musicales es numerosa y significativa en todas las fases del cubismo. Analizando la evocación musical de la pintura cubista, ésta se desvela como un impulso creativo y un puente de conocimiento en esta revolución artística que transformó el arte del s. XX. En esa ruptura con todo lo anterior en el arte, en la búsqueda de un nuevo espacio pictórico y una exploración sin límites de un nuevo lenguaje pictórico, están siempre presente la música: en los volúmenes, objetos, letras y signos.” (García Marco, 2013: 168) "El cubismo fue motivo para incesantes transformaciones, y desde entonces jamás el lenguaje de la pintura había sido tan frecuente y radicalmente alterado." (García Marco, 2013: 169)

No obstante, un vanguardista y coetáneo como Federico García Lorca "le parecían las obras de Juan Gris expresiones esquemáticas y frías, aunque reconocía la lírica que tienen las guitarras enlazadas con ese delicado sentimiento de peces nocturnos. Más comprensión recolectó la magia de sus números y sus proporciones de color por otros poetas de la Generación del 27, como Gerardo Diego. A su muerte, en 1927, escribió: Entretanto/ yo persigo el destino/ obtenido en el roce de tus pensamientos inclinados." (González, 2012)

“Gris fue considerado el más puro cubista y uno de los que llevó el movimiento a su más alto nivel. Gris a menudo inició sus trabajos con una concepción figurativa científica y abstracta.” (Stanley Johnson, 1991: 20-21)

\subsection{BIOGRAFÍA Y PENSAMIENTO ARTÍSTICO-FILOSÓFICO}

"Nacido en Madrid con el nombre José Victoriano González Pérez, conocido como Juan Gris, realiza estudios entre 1904 y 1906 en la Escuela de Artes e Industrias de Madrid, donde se aplica en matemáticas, física, ingeniería y metodología científica, así como en diversos campos de las artes, que se 
complementan en el taller del pintor paisajista y de género José Moreno Carbonero.” (Sarriugarte Gómez, 2016: 239)

"No era una casualidad que José González hubiera adoptado el nombre de Juan Gris. Este nombre tiene una resonancia particular; una resonancia que no le deja a uno indiferente. Tiene un ritmo rotundo, limpio y preciso: unas cualidades que son elementos importantes en su obra.” (Vicente, 2010)

Gris estudió en lo que "más tarde sería la Escuela Industrial y empezó a publicar sus dibujos en revistas madrileñas como Blanco y Negro o Madrid Cómico." (Jimenez-Blanco, 2013: 3) "En algunas de las viñetas se anuncian ya las composiciones de geometría marcada y la preferencia por el tema de instrumentos musicales estilizados de sus composiciones cubistas posteriores." (Jimenez-Blanco, 2013: 4)

"El ambiente artístico de Madrid no parecía estar a la altura del pasado que atestiguaba el Museo del Prado, y los artistas innovadores tenían una única salida: el viaje a París. Gris hizo este viaje con diecinueve años de edad y ya no volvió.” (Jimenez-Blanco, 2013: 4)

"El año 1912 marca su definitiva integración bajo la estela pictórica del cubismo sintético, destacando igualmente su relación con el grupo de Puteaux. Los encuentros con esta agrupación cubista le derivarán hacia postulados caracterizados por la aplicación de enrejados, que eran formulados bajo premisas matemáticas, así como un interés manifiesto por la sección aurea, pero sin ser olvidada por parte del artista la evocación de un discurso espiritual adecuado a las necesidades de su tiempo." (Sarriugarte Gómez, 2016: 238)

"En ese mismo año sigue investigando en los experimentos de Braque y Picasso, es capaz de inventar su propio estilo dentro del cubismo. Básicamente, consigue, por un lado, integrar una figura cubista descompuesta en su cuadrícula diagonal en un entorno espacial reconocible. Por otro lado, vuelve de nuevo al color y experimenta con el collage hasta alcanzar cotas que no se habían visto ni en la obra de Picasso. Esto es lo que verdaderamente conmociona de su nuevo estilo a la sociedad artística parisina." (Algargos, 2014)

“A Gris le interesó especialmente el método deductivo, basado en no crear a partir de una botella un cilindro, tal y como lo planteaba Cézanne, sino en un sentido inverso extraer de un cilindro una botella, procediendo de lo abstracto a lo figurativo, estrategia que se aprecia especialmente desde 1917, donde las propuestas lineales se simplifican.” (Sarriugarte Gómez, 2016: 239) “Un año más tarde decide pasar una temporada en Céret con Picasso, donde perfecciona el lenguaje del cubismo sintético. Por otra parte, su amistad con Picasso se irá enfriando paulatinamente a raíz de esta convivencia.” (Sarriugarte Gómez, 2016: 239)

"Juan Gris tuvo una proyección humanista y ciertamente espiritual en lo que se refiere a la búsqueda de un cubismo que estuviera integrado por pautas y constantes, como era la posible aplicación 
matemática en base a la proporción divina, con el propósito de generar un cubismo espiritual y alejado de la habitual visión mecanicista." (Sarriugarte Gómez, 2016: 251) "Con esta perspectiva, les conduce a querer plasmar la música y transformarla de objeto mental a obra de arte.” (García Marco, 2013: 168) "Uno de los artistas importantes de la vanguardia cubista, y acertó en su diagnóstico de una pintura que está en el justo medio entre lo estructural y lo estético, entre lo arquitectónico y lo sensorial, entre lo universal y lo particular.” (Jiménez Blanco, 2013: 8)

"Juan Gris no fue un artista versado en grandes apariciones estelares, su vida se caracterizó por ser recogida y mantenerse con discreción, pero por su sólida aportación al cubismo se le solicitó su opinión para revistas vanguardistas.” (Sarriugarte Gómez, 2016: 241)

Si hay alguien que puede resumir no tan solo su obra sino lo que significan los movimientos artísticos y su pensamiento filosófico es el mismo Gris: En todas las grandes épocas del arte, se siente la necesidad de representación de un mundo sustancial y espiritual. Cada época lo ha influido y diversificado según sus exigencias e inquietudes. ${ }^{1}$

\section{MARCO TEORICO}

"El aficionado a la música, experimenta, escuchando un concierto, una alegría diferente a la alegría que siente escuchando los ruidos naturales como el murmullo de un riachuelo, el estruendo de un torrente, el silbido del viendo en un bosque, o las armonías del lenguaje humano fundadas en la razón y no en la estética. Nos encaminamos hacia un arte totalmente nuevo, que será a la pintura, tal como la habíamos planteado hasta ahora, lo que la música es a la literatura. Será una pintura pura, del mismo modo que la música es literatura pura." (Apollinaire, 1913: 7)

Juan Gris, en toda su obra, confirma que la música es habitual en su vida o, lo que es más, que la música, es habitual entre los artistas de la época independientemente de si son pintores, poetas, arquitectos...

"La música tiene la particularidad dentro de las bellas artes de ser muy estimulante y producir sensaciones de forma rápida, inmediata, se pensaría que de forma inconsciente aunque no es así, la música une, la música identifica, con la música se expresan los más sinceros sentimientos, hay un lenguaje universal a través de ella, con la música muchas personas pueden expresar y sentir" (Gamboa Leguizamón, 2021: 5290)

De la misma manera, se puede afirmar que el cubismo, como elemento revolucionario artístico, es parte de la filosofía con la que artistas de otras ramas distintas a la pintura, encauzan sus obras.

\footnotetext{
${ }^{1}$ J.GRIS, Correspondencia..., p.403. Extraído de una respuesta a una encuesta a Bulletin de la Vie Artistique, 1924
} 
"No se aprecia en la pintura cubista ninguna relación a ningún otro arte como ocurre con la música, y además en momentos tan claves del cubismo.” (García Marco, 2013: 176) De hecho, es tan frecuente la presencia de elementos musicales en el cubismo que no se puede comparar con ningún otro elemento artístico pues, estos otros aparecen en mucha menor medida. Sí resulta un elemento bastante común la aparición de periódicos como símbolo decorativo, así como la representación de utensilios cotidianos.

"En sus pinturas, reproduce el papel pautado, no oculta que es pintura, y, cuando hace collage, el papel se integra plenamente en el dominio de la pintura." (Bozal, 2005). De esta manera, no solo da protagonismo a los instrumentos, sino que otras referencias musicales son una constante en sus obras.

Cabe destacar que la mayor parte del trabajo de campo se ha realizado gracias a la abundante información de la que se dispone hoy en día en internet. Resulta de gran valor y ayuda poder contar, al alcance de la mano, con herramientas que muestren la obra pictórica de Gris para llevar a cabo esta y otras investigaciones. En concreto, se habla de wikiart y www.juangris.org.

Gracias al minucioso estudio de la información disponible en las dos plataformas digitales que se citan en el párrafo anterior y, desde un punto de vista exclusivamente positivista, se demuestra que, en la obra de Juan Gris, la mayoría de sus trabajos tienen un marcado y significativo interés por la iconografía musical en un porcentaje bastante mayor que otros elementos que se nombran habitualmente en la bibliografía como característicos de su pintura, que son los utensilios de la vida cotidiana.

En el registro de datos que sigue a continuación, se puede apreciar un resumen de los resultados conseguidos gracias al estudio de dos páginas web que cuentan con un gran número de obras disponibles.

\begin{tabular}{|c|c|c|c|c|c|}
\hline & $\begin{array}{l}\text { ELEMENTOS } \\
\text { MUSICALES }\end{array}$ & PERIODICOS & UTENSILIOS & OTROS & TOTAL \\
\hline \multirow{2}{*}{ JUANGRIS.ORG } & 77 & 53 & 66 & 56 & \multirow{2}{*}{252} \\
\hline & $30,56 \%$ & $21,03 \%$ & $26,19 \%$ & $22,22 \%$ & \\
\hline \multirow{2}{*}{ WIKIART } & 64 & 44 & 51 & 37 & \multirow{2}{*}{196} \\
\hline & $32,65 \%$ & $22,45 \%$ & $26,02 \%$ & $18,88 \%$ & \\
\hline \multirow{2}{*}{ TOTAL } & 141 & 97 & 117 & 93 & \multirow{2}{*}{448} \\
\hline & $31,47 \%$ & $21,65 \%$ & $26,12 \%$ & $20,76 \%$ & \\
\hline
\end{tabular}

Asimismo, cabe destacar que un elemento que se suele citar como característico de su obra, la presencia de Pierrots y Arlequines, se ha encontrado que es escasa. Si bien, puede ser significativa porque demuestre la influencia picassiana en la pintura de Gris, no se ha considerado necesario hacer un apartado para esta figura pictórica.

En resumen, los elementos musicales corresponden a un porcentaje aproximado al $30 \%$ en ambos casos, mientras que los utensilios, dedicada a elementos de la vida cotidiana, están en segundo lugar ocupando un 26\%. En la sección de periódico, hay que destacar que muchas de 
estas obras, se podrían haber incorporado a la sección de utensilios, sin embargo, se ha decidido crear su propia sección debido a la importancia que toma este elemento en la pintura de Gris que representa un $21 \%$ de su producción pictórica.

\section{METODOLOGÍA}

Merece la pena recordar "que en su gran exposición en el año 2005 alrededor de 250 obras, entre pinturas y dibujos, muchas de ellas nunca antes expuestas en España, ilustran los principales periodos creativos del artista, maestro del cubismo sintético." (Bozal, 2005)

Sin embargo, ante la imposibilidad de contemplar esas obras en una exposición semejante hoy en día, tenemos al alcance de la mano mucho material en internet que ha sido esencial para la realización de este trabajo. Wikiart, cuenta un catálogo de 196 obras y en www.juangris.org hay disponibles la friolera de 252 obras del pintor.

Ambos espacios virtuales han sido esenciales para realizar este estudio pues hay poca bibliografía con fotografías de sus obras completas.

Los métodos utilizados para la realización de este trabajo ha sido una mezcla de métodos cuantitativos y cualitativos.

Dentro de los métodos cualitativos, se ha utilizado la observación detallada de las obras y su estudio analítico, así como la lectura intensiva de bibliografía que, en su inmensa mayoría, trata de aspectos técnicos pictóricos. Debido a ello, se ha tenido que hacer una criba importante para encontrar señales y esbozos del tema que se quería tratar, es decir, la relevancia de la música en su obra.

Por otro lado, se ha usado el método cuantitativo para demostrar, a través de una corriente positivista, la importancia tan relevante que tenía la música en la obra de Juan Gris.

\section{CONCLUSIONES}

Las conexiones del arte y la transversalidad de las manifestaciones artísticas, semejante a la conexión que hay entre los conocimientos científicos y tecnológicos con el arte, deja patente, una vez más, que la única manera que tiene la humanidad de seguir explorando, descubriendo y avanzando para salir de la barbarie en la que, según este autor, aún está sumida la raza humana, es a través de la investigación y el desarrollo en ciencia y tecnología, algo que está al alcance de muy pocas mentes privilegiadas.

Sin embargo, la evolución social también puede darse a través de cualquier tipo de manifestación artística y esto sí está al alcance de mucha más gente, ya que este autor considera que la expresión a través del arte es innata en el ser humano. Al contrario de lo que ocurre con la ciencia y la tecnología que requiere de una capacidad intelectual, formación específica y medios económicos, con el arte se puede afirmar que 
alguien absolutamente iletrado, e incluso analfabeto, tiene en su poder la capacidad de realizar creaciones artísticas de gran calado.

En resumen, solo se puede evolucionar a través de la ciencia y el arte, y este último está al alcance de la mano de quien quiera expresarse o disfrutar con él.

Si se considera lo anteriormente expresado en este trabajo, y su relación con la pintura de Juan Gris, se puede concluir que "esta nueva mirada musical es necesaria para entender la pintura cubista, y una vez más reverenciar el papel decisivo de la música en otros campos del arte. El enfoque interdisciplinar fecunda las investigaciones y, gracias a él, se dan profundos avances de otro modo imposibles. Enlazar diversas disciplinas ayuda a tener una visión más profunda, amplia y creativa." (García Marco, 2013: 168)

De hecho, en aras de esa transversalidad artística que Gris ensalza se sabe que "su relación con los poetas fue extraordinaria y sutil. Los artistas y los críticos de arte le miraron muchas veces con desconfianza." (Rodríguez, 2005: 34) "Sus amigos no sabían cómo hacer para decir maravillas de él y de su pintura. Posiblemente, fueron ellos los que mejor entendieron la pintura de Juan Gris, su poesía pintada, llena de rimas nuevas, plásticas, visuales, dichas en el lienzo, con alma de arquitecto del color y de arquitecto de las estructuras que lo ordenan.” (Rodríguez, 2005: 34)

Por otro lado, la antropología nos enseña que, a pesar de haya culturas muy rudimentarias y con pocos avances tecnológicos, ninguna está exenta manifestaciones culturales artísticas, bien en modo de música, bailes, arquitectónicas, pictóricas o de cualquier otro tipo. El arte es inherente al ser humano. Las vanguardias de comienzos del siglo XX fue una evolución artística, una tendencia de romper con lo establecido, una nueva visión del, que impregnaría a quienes vendrán posteriormente a caballo de otros movimientos artísticos como el surrealismo o el movimiento pop.

Trazando un paralelismo entre la pintura cubista y el tema que aquí se trata, que es la música, no se puede dejar pasar por alto las composiciones de Stravinski, quien fue el verdadero revolucionario de la música sinfónica de principios del siglo XX. Stravinski enlaza el más certero paralelismo entre el cubismo y su interpretación de su universo artístico. A semejanza con el nuevo estilo pictórico, "Stravinski mezcla elementos rítmicos y tímbricos frenéticos para la estética de esa época, creando asimetrías sin perder la estructura." (García Marco, 2013: 180)

"Sin los poetas, sin los artistas, los hombres se cansarían enseguida de la monotonía natural. La sublime idea que tienen del universo caería a una velocidad vertiginosa. El orden que se manifiesta en la naturaleza y que no es más que un efecto del arte se desvanecería enseguida. Todo se desharía en el caos. No más estaciones, no más civilizaciones, no más pensamiento, no más humanidad, no más vida incluso, y la impotente oscuridad reinaría para siempre. Los poetas y los artistas determinan de común acuerdo el rostro de su época y la posterioridad adopta dócilmente su opinión.” (Apollinaire, 1913: 8) 
No obstante, con los datos biográficos que se disponen no se conoce, a ciencia cierta, si Juan Gris era un ferviente melómano o si, simplemente, se ha dejado influir por la corriente de representar instrumentos musicales por parte de Braque y Picasso. En opinión del autor, Juan Gris podría haber escogido otros objetos que le hubieran sido más evocadores o inspiradores. Sin embargo, no fue así. La pintura de Juan Gris está plagada de música ya sea con instrumentos o con partituras, incluso en bodegones y retratos aparecen detalles musicales. Esta innegable preferencia por la presencia de instrumentos musicales en su obra, no deja ningún resquicio a la duda de que la música era una de las referencias principales del pintor.

Bajo estas premisas, se considera que una persona de innegable capacidad artística y una sensibilidad especial, una visión diferente del mundo, era capaz de apreciar la música hasta el extremo.

Basta como ejemplo de su capacidad artística y de su filosofía de vida, la lectura detallada de sus propias palabras: Para mí el cubismo no es un procedimiento, sino una estética, cuando no incluso una condición del espíritu... Y si es así, el cubismo debe tener una relación con todas las manifestaciones del pensamiento contemporáneo. Se puede inventar aisladamente una técnica o un procedimiento, pero no una condición espiritual. ${ }^{2}$

"Si el cubismo posee una naturaleza espiritual, qué mejor alimento para el espíritu que la música." (García Marco, 2013: 182)

2 MICHELI, Mario De: Las vanguardias artísticas del siglo XX, Alianza Forma, Alianza Editorial, S.A., Madrid, 2006, p. 187. 


\section{BIBLIOGRAFÍA}

APOLLINAIRE, G., "La pintura Cubista, Nueva Visión”, 1964, Buenos Aires, 1913: 14 páginas. Este documento se puede encontrar en un libro compilación de artículos sobre arte:

CIRLOT, L., Primeras Vanguardias Artísticas, Editorial Labor, S.A. Barcelona, 1995. pp. 59-72 http://www.terras.edu.ar/biblioteca/9/9AyE_Cirlot_Unidad_4.pdf

BOZAL, V., "La mirada sabia de Juan Gris”, El País, Madrid, 2005. https://elpais.com/diario/2005/07/02/babelia/1120259168_850215.html

GARCIA MARCO, C. "La presencia de la música en la pintura del cubismo sintético de Pablo Picasso en 1914”. Música oral del Sur, n. 10, pp. 168-182, 2013, ISSN 1138-8579: 15 páginas.

http://www.centrodedocumentacionmusicaldeandalucia.es/export/sites/default/publicaciones/pdfs/lapresencia-de-la-musica-en-la-pintura-del-cubismo-sintetico-de-pablo-picasso-en-1914.pdf

GONZÁLEZ, J., “Juan Gris vuelve cubista el logo de Google”, ABC, Madrid, 2012, pp 33-34. https://www.abc.es/20120323/cultura-arte/abci-jose-gonzalez-pintor-quiso-201203230947.html

RODRÍGUEZ, D., "En el Reina Sofía, Más Gris”, ABC Cultural, Madrid, 25/6/2005, pp. 32-34: 3 páginas

SARRIUGARTE GÓMEZ, I., "La sección d'or y Juan Gris: un camino hace un cubismo espiritual", Universidad del País Vasco, De Arte, 15, 2016, pp. 238-251: 14 páginas.

http://www.academia.edu/30788327/I._Sarriugarte_G\%C3\%B3mez_La_Section_d_Or_y_Juan_Gris_U n_camino_hacia_un_cubismo_espiritual

VICENTE, E., “La realidad cúbica de Juan Gris”, La Jornada Semanal, Núm. 774, Madrid, 2010. http://www.jornada.unam.mx/2010/01/03/sem-esteban.html

GAMBOA LEGUIZAMÓN, L.M., "De las Bellas Artes a la Composición Arquitectónica”, South Florida Publishing, South Florida Journal of Development, 2021, Vol. 2 No. 4, 2021 pp.5285-5295: 11 páginas https://southfloridapublishing.com/ojs/index.php/jdev/article/view/690/624

Libros:

MICHELI, M., Las vanguardias artísticas del siglo XX, Alianza Forma, Alianza Editorial. S.A., Madrid, 2006.

STANLEY JOHNSON R., Cubism \& La Section d'Or: Reflections on the Development of the Cubist Epoch 1907-1922, University of Washington Pr., Chicago-Düsseldorf, 1992.

Blogs de arte:

ALGARGOS, Juan Gris, Pintor del Cubismo sintético, 2014

http://algargosarte.blogspot.com.es/2014/10/juan-gris-pintor-del-cubismo-sintetico.html?m=1

Folleto publicado por el Museo Reina Sofía de Madrid:

JIMÉNEZ-BLANCO, M.D., El cubismo y los orígenes del arte del siglo XX. Cubismo y Clasicismo: El lugar de Juan Gris en el relato cubista, Museo Thyssen-Bornemisza, Madrid, 2013: 18 páginas. 
https://imagenes.educathyssen.org/sites/default/files/document/2017-

02/encuentroanteobras_cubismo_adultos_pp_edu.pdf

Espacios virtuales:

http://www.juangris.org/the-complete-works.html

https://www.wikiart.org/en/juan-gris 